\title{
BMJ Open Effectiveness of vocational interventions for gaining paid work for people living with mild to moderate mental health conditions: systematic review and meta- analysis
}

Joanna K Fadyl (D) , ${ }^{1}$ David Anstiss, ${ }^{1}$ Kirk Reed, ${ }^{1,2}$ Mariya Khoronzhevych, ${ }^{3}$ William M M Levack (1) ${ }^{4}$

To cite: Fadyl JK, Anstiss D, Reed K, et al. Effectiveness of vocational interventions for gaining paid work for people living with mild to moderate mental health conditions: systematic review and meta-analysis. BMJ Open 2020;10:e039699. doi:10.1136/ bmjopen-2020-039699

- Prepublication history and additional materials for this paper is available online. To view these files, please visit the journal online (http://dx.doi org/10.1136/bmjopen-2020039699).

Received 23 April 2020 Revised 31 July 2020 Accepted 25 September 2020

Check for updates

(C) Author(s) (or their employer(s)) 2020. Re-use permitted under CC BY-NC. No commercial re-use. See rights and permissions. Published by BMJ.

For numbered affiliations see end of article.

Correspondence to

Joanna K Fadyl;

joanna.fadyl@aut.ac.nz

\section{ABSTRACT}

Objectives To evaluate the effectiveness of vocational interventions to help people living with mild to moderate mental health conditions gain paid work.

Methods Systematic review of international, peerreviewed literature. Development of the prepublished protocol and search strategy was done in consultation with stakeholder reference groups consisting of people with lived experience of long-term conditions, advocates and clinicians. We searched academic databases MEDLINE, EMBASE, PsychINFO, AMED, CINAHL, Proquest Dissertations and Theses database, and Business Source Complete for controlled trials comparing a specific vocational intervention against a control intervention or usual care, published between 1 January 2004 and 1 August 2019. Two authors independently screened search results, extracted data and appraised studies using the Cochrane risk of bias tool.

Results Eleven studies met inclusion criteria. Seven studies investigated Individual Placement and Support (IPS) modified for people who were not in intensive mental health treatment services. These studies occurred settings such as community vocational rehabilitation services, a housing programme and community mental health services. The studies provided very low quality evidence that people who receive IPS-style vocational rehabilitation are more likely to gain competitive employment than people who receive usual care (risk ratio 1.70, 95\% Cl 1.23 to 2.34, seven studies, 1611 participants). The remaining four studies considered cognitive behavioural therapy or specific vocational rehabilitation interventions designed to fit a unique context. There was insufficient evidence from these studies to draw conclusions regarding the effectiveness of non-IPS forms of vocational rehabilitation for people with mild to moderate mental health conditions.

Discussion The meta-analysis showed a clear intervention effect but low precision, and more highquality studies are needed in this field. There is currently very low quality evidence that IPS-style intervention results in more participants in competitive employment compared with 'usual care' control groups in populations with mild to moderate mental health conditions.
Strengths and limitations of this study

- This is the first systematic review and meta-analysis looking at interventions to support people living with mild to moderate mental health conditions to gain paid work

- A rigorous, prepublished systematic review protocol was used, informed by stakeholder consultation.

- Conclusions are limited by the number of studies and the methodological quality of those studies.

\section{INTRODUCTION}

People who experience chronic health conditions and/or disability often have difficulty accessing paid work due to a number of complex factors. These factors include stigma, poorly informed judgements about what makes somebody 'work-able', fear of negatively affecting health and safety in the workplace or making the workplace vulnerable to higher costs, and challenges in negotiating work arrangements that are outside the norm when needed. ${ }^{1-5}$ Case management, vocational rehabilitation and employment support can all help to address these challenges to improve work outcomes for people experiencing health conditions and/or disability, and various approaches exist within these broad categories that have been tested in research.

Supported employment is a type of vocational rehabilitation that focuses on securing paid work for people then providing them support to become competent in that role while working. ${ }^{6}$ This is in contrast to an approach that might instead delay entry into the workplace until people are deemed to be fully trained and independent workers. In mental health, a particular approach to supported employment has been developed 
for people diagnosed with severe mental health conditions-Individual Placement and Support (IPS). ${ }^{7}$ IPS is characterised by several standardised principles, which can be measured using a fidelity scale. ${ }^{8-10}$ A summary of the main principles of IPS are as follows:

- IPS is provided by employment specialists with low caseloads (20 or fewer).

- No exclusion criteria-IPS is provided to any people who wants a job.

- Integrated with mental health treatment-employment specialists are treated as a discipline within a mental health multidisciplinary team.

- Employment specialists work with clients across all phases of their vocational journey.

- Integrated with financial advice and work incentives planning.

- Individualisation of job searches to each person's interests and skills.

- Rapid job search for competitive employment.

- Employment specialists are actively engaged in job development on behalf of their clients (relationships with employers, actively seeking to create individualised opportunities).

- Ongoing support once working, as appropriate to each situation.

While IPS has been designed for people in intensive treatment services for mental health and addiction, positive outcomes from this approach have prompted adaptation into other populations. ${ }^{11}$ The adaptations have varied according to context, but include locating the employment specialist within a team that is focused on interventions other than mental health treatment, ${ }^{12} 13$ and/or the addition of more explicit empowerment components. ${ }^{12} 14$

Several systematic reviews have been published on the effectiveness of vocational interventions for people with severe mental health conditions such as severe depression, bipolar disorder and psychotic conditions. ${ }^{15-24}$ The most recent of these reviews was a network meta-analysis, ${ }^{24}$ which met almost all of the criteria of the AMSTAR-2 assessment tool for assessing the quality of systematic review. ${ }^{25}$ This network meta-analysis concluded that there was low quality evidence that supported employment was effective in aiding people diagnosed with severe mental health conditions to gain competitive employment (relative risk (RR) $2.72,95 \%$ CI 1.55 to 4.76 ) and moderate quality evidence for augmented supported employment (RR 3.81, 95\% CI 1.99 to 7.31) when compared with psychiatric care alone. To the best of our knowledge, however, no systematic reviews have been conducted on vocational interventions for people with mild to moderate mental health conditions.

Mild to moderate mental health conditions are common globally. ${ }^{26}$ Additionally, some people experience mental health symptoms that are subthreshold for diagnosis. These people are at risk of being missed in service delivery. ${ }^{27}$ Mental health conditions, particularly anxiety and depression, are a major concern as contributors to work incapacity, ${ }^{28}$ but people with mild to moderate depression and anxiety are not typically included in clinical trials that test vocational rehabilitation or employment support interventions designed specifically for mental health populations. Arguably, the most effective way of preventing work disability for people experiencing mild to moderate mental health conditions is to provide support to maintain existing employment, as psychosocial issues within and outside of the workplace have been shown to be significant predictors of failure to return. ${ }^{29}$ Furthermore, long periods away from work lead to less likelihood of return. ${ }^{29}$ However, it is common for people to be out of work before they seek support, and often the support provided is done through social insurance agencies that also manage unemployment benefits. Because of this, effective interventions that are designed to support people to gain and maintain new employment are vital. The aim of this systematic review therefore was to evaluate the effectiveness of interventions for providing support for gaining employment to unemployed people with mild to moderate mental health conditions.

\section{Consultation with stakeholder reference groups}

Although systematic reviews are often seen to be 'objective', they are not impartial, as the design of the search strategy and assessment of relevance affects what literature is accessed and included..$^{30}$ Further to this, the way in which findings are reported and made relevant to the local context is crucial in how the information is used in practice. Explicit stakeholder involvement in systematic review processes to address external validity and transferability of findings is a recent development in systematic review design. ${ }^{31}$ Our methods included explicit involvement of stakeholders in informing the design, contextualisation and reporting of the review.

\section{Review questions}

1. What is the effectiveness of vocational interventions to help adults with mild to moderate mental health condition(s) gain and maintain paid work in comparison to no treatment, an attention control or usual vocational services?

2. What is the quality of evidence on vocational interventions to help adults with mental health condition(s) gain and maintain paid work?

3 . What evidence gaps exist in relation to vocational interventions to help people with mild-moderate mental health condition(s) gain and maintain paid work?

\section{METHODS}

For this review, we followed the methods recommended by the Cochrane Handbook for Systematic Reviews of Interventions. ${ }^{32}$

\section{Patient and public involvement}

Stakeholder reference group consultation

At three key stages in the process-protocol development, considering transferability and external validity of the evidence profile and dissemination of findings-we 
consulted with two stakeholder reference groups. The condition-specific stakeholder reference group was made up of people with lived experience of mild to moderate mental health conditions and people involved in services and advocacy in this field. We also consulted a specific Māori stakeholder reference group (indigenous culture of Aotearoa New Zealand in which the review was undertaken) that included people with professional and personal experience across a range of long-term conditions. The reason for having a separate Māori group is that Indigenous perspectives are often overlooked and/or under-represented in mainstream research. The protocol and search strategy for this study was refined with the stakeholder groups and prepublished before we searched the literature. ${ }^{33}$ The stakeholder reference groups were involved again later to provide input into contextualising findings for the local context and peoples, and assisted with various methods of dissemination in the community including meetings, discussions, webinars and userfriendly summaries.

\section{Criteria for considering studies for this review \\ Type of studies}

We included randomised controlled trials (RCTs), cluster RCTs, pseudo-RCTs and non-RCTs that assess the effects of vocational interventions for unemployed people with mild to moderate mental health conditions. We included published, peer-reviewed literature and theses and dissertations. We excluded studies that were not published in English. We included the various types of controlled trials so as to be inclusive as possible, anticipating a low number of studies due to this being a relatively new area.

\section{Type of participants}

We included studies where participants were 16 years of age or older, who had a mild to moderate mental health condition and were unemployed at study outset. We defined a mild to moderate mental health condition as living with symptoms that indicate a mild to moderate mental health condition (eg, anxiety, depression) regardless of whether or not the person had been given a formal diagnosis. To operationalise this definition, we excluded diagnoses that frequently require specialist intervention (eg, inpatient, community mental health team) such as bipolar, schizophrenia and psychotic conditions. More commonly, mild to moderate mental health conditions such as mild to moderate anxiety and depression are either managed in general practice or go undiagnosed.

Because of the difficulty in capturing mild-moderate severity using keywords, we did not limit the search by severity, but excluded studies that focused on 'severe' diagnoses at the assessment of relevance stage. Where studies included a mix of participants who met our definition of mild-moderate severity and also participants with greater severity, we included the study if the proportion of participants meeting our inclusion criteria was $60 \%$ or greater. We based this decision on an assumption that where the intervention is appropriate for a range of severities, participants with more severe diagnoses are more likely to affect outcomes negatively rather than positively.

For the purpose of this review, participants were considered unemployed if they were not in paid work. We defined paid work according to the Resolution concerning statistics of the economically active population, employment, unemployment and underemployment, adapted by the Thirteenth International Conference of Labour Statisticians (October, $1982)^{34}$ or as a legal occupation that generates a livelihood (eg, Indigenous practices that generate resources to live on but are not paid employment).

\section{Type of interventions}

Employment support services considered in scope included the following:

- Training or education to prepare people to apply for employment (eg, preparation of resumes; development of work skills; job-specific skills training and licencing (eg, drivers licence), training in employment interview techniques; motivational and behavioural interventions to help people increase their self-efficacy for employment and engage in work).

- Vocational counselling to help people identify their work skills and aptitude, seek work, or find and apply for jobs.

- Provision of support for people to apply for jobs or actively seek employment in other ways (including peer support programmes).

- Identification of environmental barriers to employment (eg, workplace, transport or attitudinal barriers) and implementation of supports and/or strategies to reduce or remove those barriers (eg, job accommodation, workplace modification-including access, provision of equipment, employer education, supporting workplace relationships and other psychosocial interventions, negotiating health and safety requirements, providing adapted transport).

- Job development (eg, working with employers to create non-standard or modified positions).

- Job placement schemes.

- Provision of support for people newly in employment.

- Provision of financial and related supports to move into employment (eg, appropriate clothing, equipment, transportation, transitional loans).

- Job coaching (short or long-term) to develop skills and strategies to manage a job.

- Community development specifically focused on creating employment opportunities for people living with long-term conditions and/or disabilities (eg, development of business initiatives that need employees with lived experience of disability, employer awareness, incentive programmes, social enterprises focused on work for this population).

- Community and family support initiatives focused on enabling participation in paid work.

- Work-readiness training or transitional employment where the focus was on transitioning into paid employment or providing skills for people to immediately 
enter paid employment at the completion of the training.

We excluded studies that focused on stay-at-work interventions for people who are currently in paid work and needing to maintain that work in the context of mild to moderate mental health conditions. We excluded sheltered workshops where the expectation is that participants will earn less than minimum wage and retain social welfare benefits for the foreseeable future. We also excluded interventions that were focused on helping people to gain or maintain occupational roles and activities that are unpaid and also unlikely to provide a livelihood.

\section{Type of comparisons}

We included studies with a no intervention control, an attention control (ie, a Hawthorne control) or a comparison to 'usual care' as defined by the study authors. We also included studies that compared two different approaches to vocational rehabilitation.

\section{Types of outcomes}

\section{Primary outcomes}

The main outcomes for the review were (1) commencement of either full-time or part-time paid work; (2) successful maintenance of new paid work for 6 months or longer.

We extracted data on rates of work placement in any type of paid work, and whether these placements were full-time or part-time; casual, fixed term or permanent (where reported). We did not consider gaining an employment contract alone to constitute commencing work if no paid work was carried out. We extracted data on maintenance of new work using count data (eg, number of people maintaining employment at 6 months) and continuous data (eg, duration of time employment has been maintained by the end of a study) as reported by the study authors. We considered outcomes at three time points: the end of intervention (as reported by study authors); up to 1 year after the end of an intervention; more than 1 year after end of an intervention.

\section{Secondary outcomes}

Where reported, we also extracted data on the following outcomes: proportion of full time work, satisfaction of employers with employment outcomes or work performance, satisfaction of participants with work outcomes, pay rates, cost of vocational interventions, cost of ongoing work support, quality of life, cost-benefit analyses, community participation, financial autonomy, selfesteem, self-efficacy, effect on health status, tensions between work expectations and requirements for rehabilitation, treatment or healthcare needs (eg, time to go to specialist appointments). We have not reported on these in this paper as there was insufficient data to draw conclusions.

\section{Study identification and selection}

We searched published literature and theses and dissertations located in seven databases: MEDLINE (OvidSP), EMBASE (OvidSP), PsychINFO (OvidSP), AMED (OvidSP), CINAHL (EBSCOhost), Proquest Dissertations and Theses database and Business Source Complete (EBSCO). Search strategies were designed and tailored to each database using key words and subject heading terms. The detailed search strategy for MEDLINE was included as an appendix to the prepublished protocol. ${ }^{33}$ Database searches covered 1 January 2004 to 1 August 2019. This was that timeframe that authors considered to be appropriate for ensuring relevancy of policies and systems relating to vocational rehabilitation.

Covidence software was used to manage the selection process (Veritas Health Innovation, Melbourne, Australia, www.covidence.org). Two review authors per study (from JF, DA and KR) independently considered each study against prespecified inclusion criteria. Initially, titles and abstracts from the identified studies were screened and studies that may meet inclusion criteria were included for full-text review. Disagreement or uncertainty about relevance was resolved through consideration and discussion of full study reports, involving an additional reviewer where necessary.

\section{Data extraction}

Two authors extracted the data from all included studies into a prespecified form (DA and MK) which was then checked by a third author, who prepared the summary tables (JF). We extracted data on study population and context, methods, interventions and their implementation and primary and secondary outcomes for our review.

\section{Risk of bias assessment}

We used the Cochrane risk of bias tool ${ }^{35}$ to assess the quality of each included study. This is a seven-item tool for assessing the risk that the results of in a controlled trial are subject to bias from aspects of the study design or execution. We scored 'yes', 'unclear' or 'no' for each item and the risk of bias as 'low', 'unclear' or 'high' for each study overall. Study authors were contacted for clarification, and responses included in assessment if we received a response.

\section{Data synthesis}

In our prepublished protocol, we only described methods for reporting on study findings descriptively because we had not anticipated finding sufficient studies of a similar nature to conduct a meta-analysis. However, as we found a number of similar studies that tested the effectiveness of interventions based on an IPS approach, we change our methods to include a meta-analysis of this evidence.

We conducted the meta-analysis according to methods in the Cochrane Handbook for Systematic Review of Interventions. ${ }^{35}$ We analysed dichotomous 
data related to successful employment outcomes using RRs. We conducted our analysis on the basis of per-person randomisation. All included studies were parallel RCT designs. We did not include data from cluster or cross-over RCTs. Where studies had more than two participant groups, or analysed subgroups separately, we only included data from the groups or subgroups relevant to our review question. For studies where data were collected at more than one time point, we only included data from the furthest time point from the studies' enrolment. We used the $\mathrm{I}^{2}$ statistic to measure heterogeneity among the trials in each analysis. We did not have enough studies to explore causes of heterogeneity by any subgroup analysis. We also did not have enough studies to use funnel plots to explore small-study and publication biases. We undertook sensitivity analyses to examine the influence of risk of bias associated with including the studies in each meta-analysis. We removed studies at the greatest risk of bias (ie, those that failed to randomise adequately or failed to conceal random allocation) from the analysis in order to test the strength of evidence for the various effect estimates.

We used GRADEPro to evaluate the quality of evidence arising from this review. ${ }^{36}$ Following the GRADE approach, we upgraded or downgraded the quality of evidence based on assessment of risk of bias, inconsistency, indirectness, imprecision and other considerations such as publication bias, size of effect, evidence of any dose response gradients and plausible confounding variables.

\section{RESULTS}

\section{Results of the search}

As illustrated in figure 1, we identified 4828 citations from the database searches in total. Of these, 3255 remained after removal of duplicates $(n=1573)$. After we had screened all titles and abstracts, we identified 33 potentially relevant studies in full text. Of these 33 titles, we included 11 studies and excluded 22. The reason for these exclusions are listed in online supplemental studies excluded at full text review.

\section{Characteristics of included studies}

The 11 included studies included a combined total of 2416 participants in the groups relevant to our review. These studies were conducted in the USA $(n=4)$ Sweden $(n=2)$, Norway $(n=2)$, Netherlands $(n=1)$, Denmark $(n=1)$ and Canada $(n=1)$. Three of the studies from the USA were focused specifically on an armed forces veteran population. The risk of bias profile across the included studies is shown in figure 2. Three studies ${ }^{12} 2737$ were evaluated as being of low risk of bias, four studies ${ }^{14-40}$ of unclear risk of bias and four studies ${ }^{13} 41-43$ of high risk of bias.



Figure 1 Preferred Reporting Items for Systematic reviews and Meta-Analyses flowchart.

The included studies covered a range of interventions that we grouped into three categories:

- IPS approaches modified for people who are not in intensive mental health treatment.

- Cognitive behavioural therapy with work-focused components.

- Other interventions.

\section{Description and synthesis of study findings} IPS approaches

Seven studies investigated the effectiveness of IPS interventions including two studies of low risk of bias, ${ }^{12} 27$ two of unclear risk of bias ${ }^{1439}$ and three of high risk of bias. ${ }^{13} 4243$

The particular context varied for each study, as did the adaptations made for the different population. All studies tested IPS in a mild-moderate mental health condition population, which differed from the population IPS was originally designed for. In most studies, the setting was also different-that is, it was not delivered in a specialist mental health treatment setting. In some studies, the study team also slightly adapted the IPS intervention principles. However, in each case, the core principles of IPS were adhered to, and existing IPS fidelity scales were used. Most of the reported studies used an IPS fidelity scale to assess both the intervention and control condition, demonstrating that the control condition achieved a score that indicated 'not-IPS'. The longest reported follow-up point ranged from 8 months to 24 months from beginning the intervention, with the median being 18 months.

See table 1 for details on the characteristics of the seven studies testing IPS interventions, and table 2 for further 


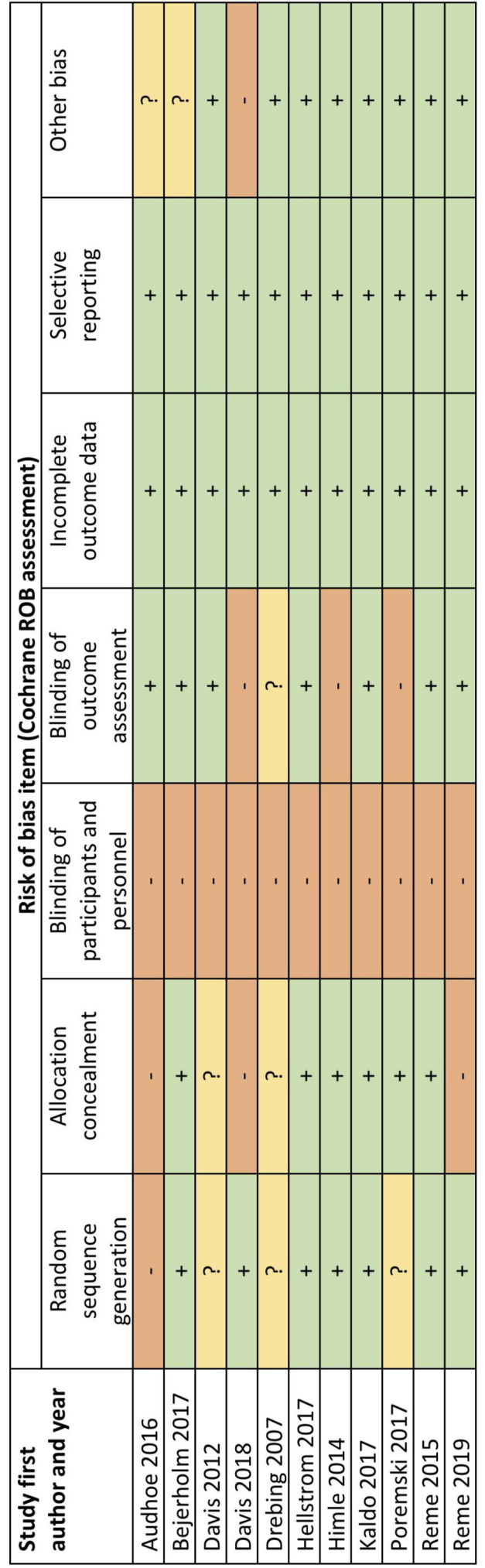

Figure 2 Risk of bias assessment by study increased likelihood of unemployed people with mild to moderate mental health conditions gaining employment when compared with a usual care approach (RR 1.70, 95\% CI 1.23 to 2.34, seven studies, 1611 participants). Removal of studies at the greatest risk of bias (ie, those that failed to randomise adequately or failed to conceal random allocation) ${ }^{18} 3944$ shifted the pooled risk ratio more in favour of an IPS style of vocational intervention, with a widening of the $95 \%$ CI (RR 2.35, 95\% CI 1.18 to 4.65).

Following the GRADE approach, we downgraded the quality of evidence underpinning this finding because of very serious problems with inconsistency (due to large statistical heterogeneity) and serious problem with imprecision (due to the wide 95\% CIs). This meant that the overall certainty of evidence supporting this finding was very low. The addition of a single large, well-conducted clinical trial in the future could easily change our estimated effect size for this comparison.

\section{Cognitive behavioural therapy focused interventions}

Two studies investigated the effectiveness of cognitive behavioural therapy as supplement to vocational services in comparison to physical exercise or treatment as usual for unemployed people with mild-moderate mental health conditions. This included one study of low risk of bias $^{37}$ and one of unclear risk of bias. ${ }^{38}$ The low risk of bias study was a US-based pilot study $(n=58)$ where cognitive behavioural therapy was delivered in the context of vocational services. ${ }^{38}$ The other study was a large Swedish study where cognitive behavioural therapy was delivered via the internet, and included work-related modules. ${ }^{37}$ Not all participants in the latter study were relevant to our review question, but this study included a subgroup analysis of participants with mild to moderate mental health conditions who were unemployed at the study outset $(n=98)$. The characteristics of these studies are presented in tables 3 and 4 . Neither of the studies reported statistically significant results on employment outcomes. The overall certainty of evidence supporting this finding was very low.

\section{Other interventions}

The remaining two included studies were focused on two different interventions, were designed for very specific population groups and were assessed as having unclear ${ }^{40}$ or high risk of bias. ${ }^{45}$ These studies investigated an intervention focused on 'activation, ${ }^{45}$ and an incentive-based contingency management programme. ${ }^{40}$ A summary of these studies is presented in table 5 .

\section{DISCUSSION}

This systematic review has found very low quality evidence that the IPS approach, modified for people who are not in intensive mental health treatment services, is effective to assist unemployed people living with mild to moderate mental health conditions 
Table 1 Study characteristics for IPS interventions in mild-moderate mental health populations

\begin{tabular}{|c|c|c|c|c|}
\hline Reference & Population & Intervention & Comparison & Fidelity information \\
\hline $\begin{array}{l}\text { Bejerholm } \\
\text { et al, } \\
2017^{14}\end{array}$ & $\begin{array}{l}\text { Depression or } \\
\text { bipolar (majority } \\
\text { this sample } \\
\text { depression) }\end{array}$ & $\begin{array}{l}\text { Individual Enabling Support } \\
\text { (IES) (principles 3-10 as for } \\
\text { IPS) }(n=33)\end{array}$ & $\begin{array}{l}\text { Traditional vocational } \\
\text { rehabilitation - 'train then } \\
\text { place' }(n=28)\end{array}$ & $\begin{array}{l}\text { Good fidelity as measured at } 6 \\
\text { and } 12 \text { months using Supported } \\
\text { Employment Fidelity Scale } \\
\text { (SEFS) } 2008^{8} \text { (delivery score } \\
\text { 106-109) }\end{array}$ \\
\hline $\begin{array}{l}\text { Davis et al, } \\
2012^{43}\end{array}$ & $\begin{array}{l}\text { Veterans with Post } \\
\text { Traumatic Stress } \\
\text { Disorder }\end{array}$ & IPS (n=42) & $\begin{array}{l}\text { Usual care in Veterans Health } \\
\text { Administration Vocational } \\
\text { Rehabilitation Programme } \\
(n=43)\end{array}$ & $\begin{array}{l}\text { Fidelity on SEFS } 1997^{9} \text { fair (55- } \\
65 \text { ) throughout study }\end{array}$ \\
\hline $\begin{array}{l}\text { Davis et al, } \\
2018^{42}\end{array}$ & $\begin{array}{l}\text { Veterans with Post } \\
\text { Traumatic Stress } \\
\text { Disorder }\end{array}$ & IPS $(n=271)$ & Transitional work $(n=270)$ & $\begin{array}{l}\text { Fidelity on SEFS } 1997^{9} \text { poor (55) } \\
\text { in first } 3 \text { months, but good fidelity } \\
\text { (63-69) maintained after that }\end{array}$ \\
\hline $\begin{array}{l}\text { Hellström } \\
\text { et al, } \\
2017^{12}\end{array}$ & $\begin{array}{l}\text { Affective disorder } \\
\text { or anxiety, no } \\
\text { mental health } \\
\text { service last } 3 \\
\text { years }\end{array}$ & $\begin{array}{l}\text { IPS modified for mood and } \\
\text { anxiety disorders (IPS-MA) } \\
(n=162)\end{array}$ & $\begin{array}{l}\text { Usual services offered by job } \\
\text { centres in Denmark }(n=164)\end{array}$ & $\begin{array}{l}\text { High fidelity throughout study on } \\
\text { IPS- } 25^{9}(100-103)\end{array}$ \\
\hline $\begin{array}{l}\text { Poremski } \\
\text { et } a l \\
2017^{13}\end{array}$ & $\begin{array}{l}\text { Recently } \\
\text { homeless, with } \\
\text { mental illness }\end{array}$ & IPS $(n=44)$ & $\begin{array}{l}\text { Community-based services } \\
\text { including some case manager } \\
\text { support }(n=41)\end{array}$ & $\begin{array}{l}\text { Fidelity on IPS }-25^{10} \text { initially fair } \\
\text { (73) and gradually increased. } \\
\text { Good (100) by final } 8 \text { months of } \\
\text { intervention }\end{array}$ \\
\hline $\begin{array}{l}\text { Reme et } \\
a l, 2015^{27}\end{array}$ & $\begin{array}{l}\text { Mainly anxiety } \\
\text { and/or depression, } \\
\text { including } \\
\text { subthreshold for } \\
\text { diagnosis }\end{array}$ & $\begin{array}{l}\text { At work and coping: } \\
\text { work-focused cognitive } \\
\text { behavioural therapy } \\
\text { alongside IPS adapted for } \\
\text { a population with mild- } \\
\text { moderate mental health } \\
\text { conditions ( } n=177)\end{array}$ & $\begin{array}{l}\text { Standard services from health } \\
\text { professionals and national } \\
\text { insurance office }(n=177)\end{array}$ & $\begin{array}{l}\text { Fidelity tested postrecruitment } \\
\text { using IPS- } 25 .{ }^{9} \text { Reported as } \\
\text { achieving 'adherence to IPS', no } \\
\text { individual scores given }\end{array}$ \\
\hline
\end{tabular}

*Fidelity indicates the level of coherence of the intervention as implemented and practiced with the principles of IPS. Scores range from 'not-IPS' upward. Various fidelity scales were used. We have reported the scale, the reported interpretation and the scores where available. Possible high scores are 125 for SEFS 2008 and IPS-25; 77 for SEFS 1997.

to gain competitive, paid work. More high-quality studies are needed and further studies are likely to change the estimate of effect. There was inconclusive evidence in relation to cognitive behavioural therapy and other approaches as interventions to support gaining paid work.

Strengths of the review were that it covered a wide range of databases and the protocol and search strategy were informed by consultation with clinicians, advocates and people with lived experience of long-term conditions. The involvement of stakeholder reference groups added value in a number of ways, which is consistent with the increased attention on this practice in recent methodological discussion. ${ }^{31}$ While the groups did not participate in the execution of the systematic review, they had important input into the protocol (which influenced inclusion criteria) and contextualisation of findings. For example, the Indigenous stakeholder reference group advised the research team to broaden the definition of 'paid work' in the protocol to include indigenous practices and other activities that generate livelihood that may not be considered 'employment'. We found this to be an important critique of the ways in which the outcomes of vocational interventions are usually conceptualised. Furthermore, both groups were able to provide extensive discussion on condition-related language and terminology that the research team were able to test out in scoping searches in order to develop an inclusive search strategy. Stakeholder reference groups were also able to provide valuable input for discussing findings in a way that was understandable with reference to both lived experiences of people 


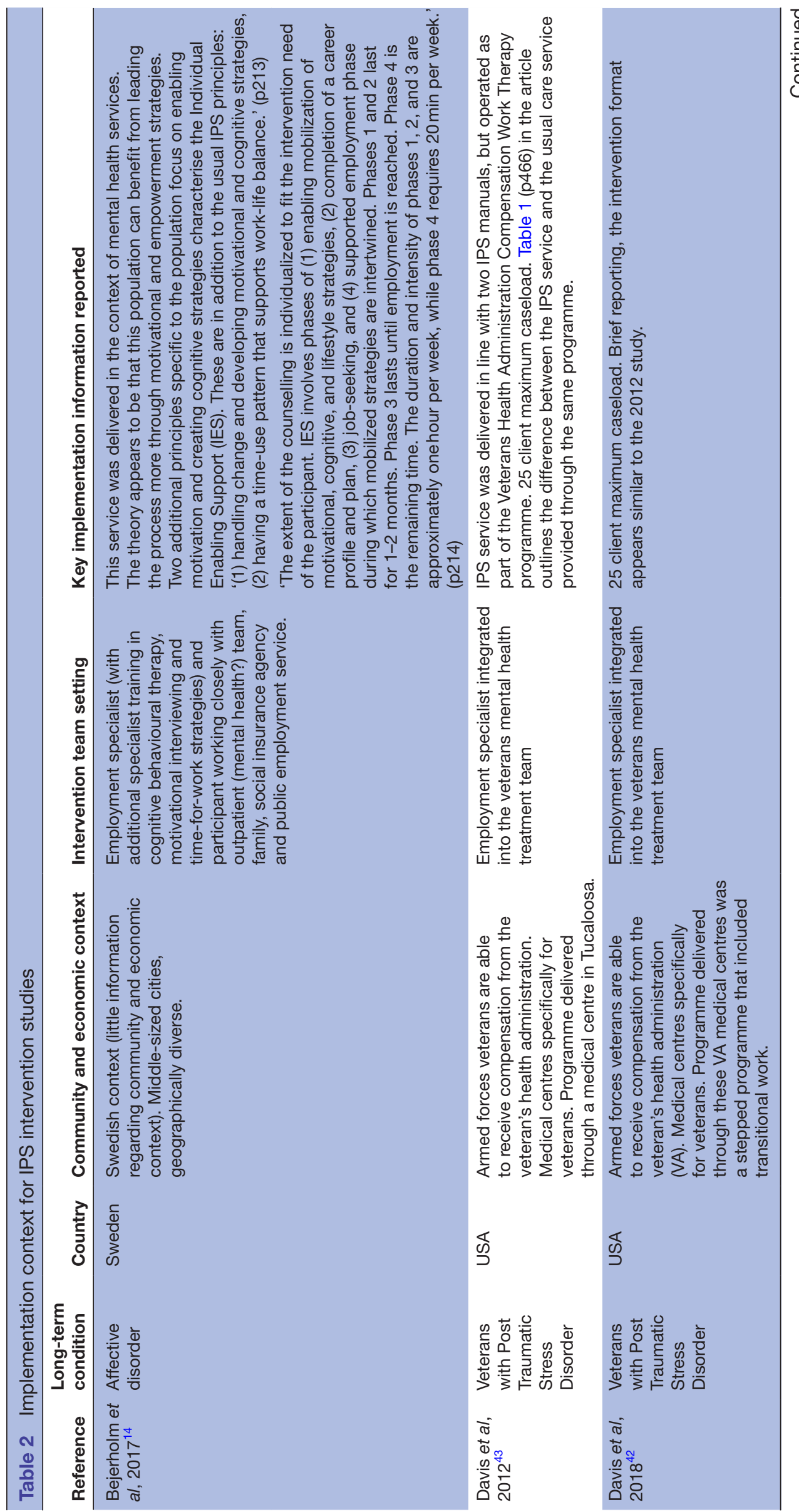




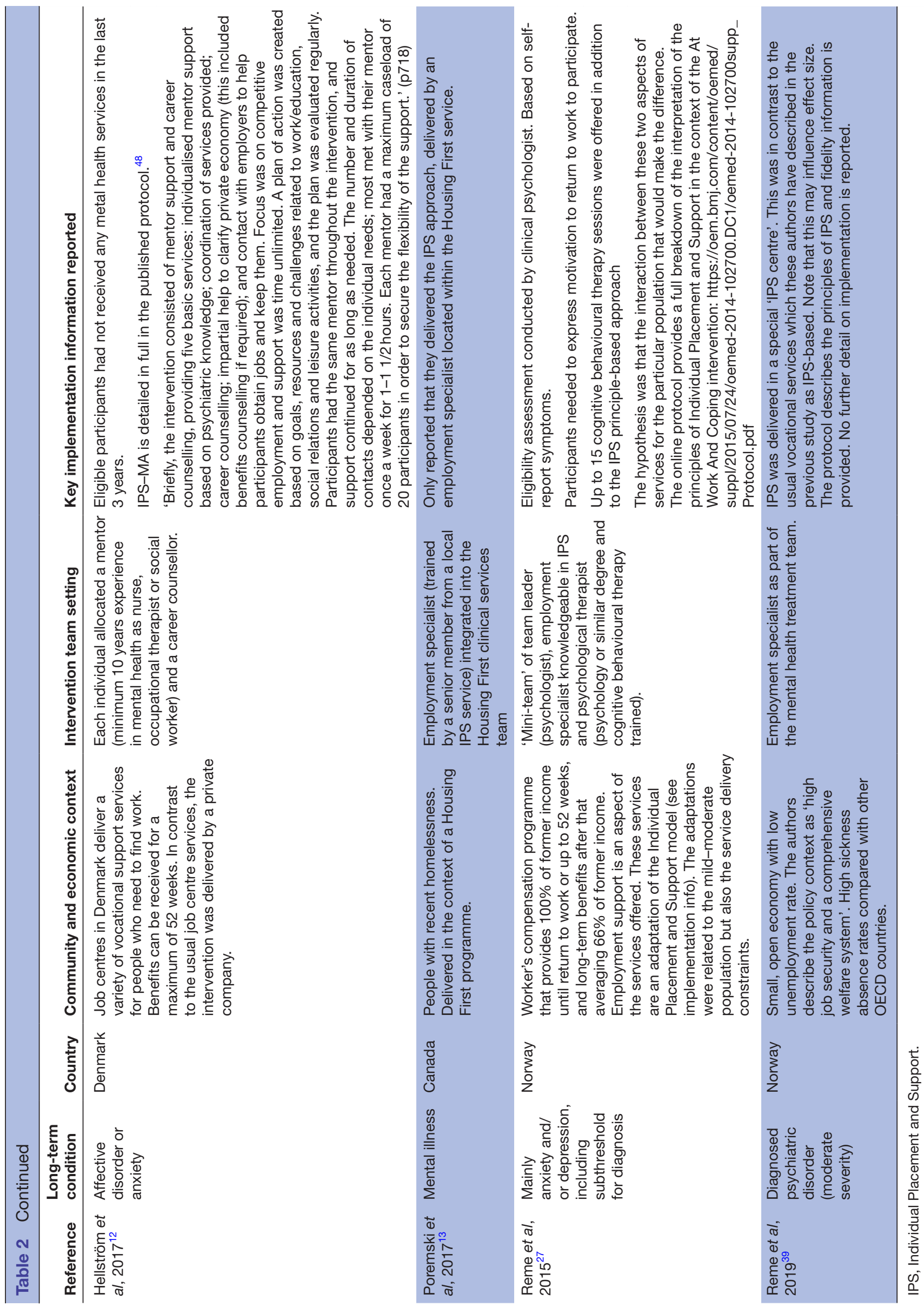




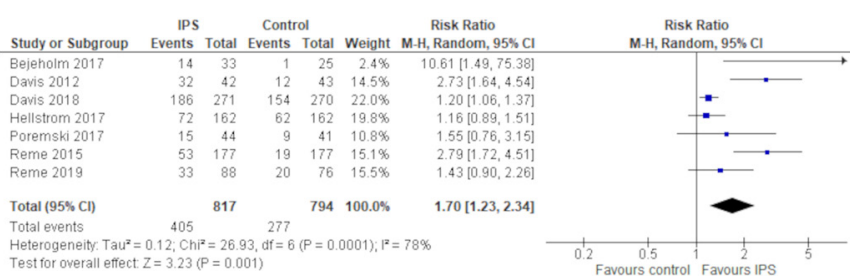

Figure 3 Forest plot Individual Placement and Support for employment, mild to moderate mental health.

living with mental health conditions and also existing service provision and funding discourses.

The review was limited by the exclusion of studies that were not reported in English, reliance on databases that index peer-reviewed journals and thesis repositories, and lack of grey literature beyond theses. As such, the conclusions we were able to draw from this systematic review and meta-analysis do not take into account the results of studies that were published in other languages or in sources not indexed in the databases we utilised. The meta-analysis in relation to the IPS approaches showed a clear intervention effect but had low precision, limited by the relatively small number of studies and participants and by large statistical heterogeneity across the studies. Because of these factors, results should be interpreted cautiously. It is also worth noting that the specific intervention settings varied considerably. The justification for metaanalysis was based on the fact that the IPS principles were followed in each situation. However, even where the same principles are implemented, knowledge of the ways in which this is done in different settings is important for clinical application. Implementation case studies and qualitative work is important for understanding the various ways of operationalising the principles. While most of these studies currently are based on the intensive mental health treatment services setting, they offer critical information on real-world implementation. Two recent examples are a critical analysis of implementation of IPS in rural New Zealand ${ }^{46}$ and a longitudinal analysis of the implementation of IPS in an Italian setting, including participants with 'moderate' diagnoses. ${ }^{47}$

As far as we are aware, this is the first systematic review to address employment support interventions for unemployed people living with mild to moderate mental health conditions. One recent review by Bond and colleagues ${ }^{11}$ looked at studies reporting on IPS in any population other than 'serious mental illness', and included a meta-analysis. There was considerable overlap in the studies used for Bond et al's metaanalysis and ours. However, Bond et al did not include one relevant study on vocational rehabilitation for people with mild to moderate mental health conditions ${ }^{13}$ and included three other studies unrelated to this review: two on people with substance use disorder and one on people with spinal cord injury. The estimate from the Bond and colleagues meta-analysis is also in favour of IPS, but with wider CIs (OR 2.23, $95 \%$ CI 1.53 to 3.24 ).

While many existing vocational interventions are currently provided worldwide, with the intent of supporting people into paid work, very few of these interventions have ever been tested in controlled trials. Most of the studies in this review compared the vocational rehabilitation intervention being tested against 'usual care'. What constituted 'usual care' was not always well described, but generally involved some form of case management and referral to services classified as 'vocational' such as skills workshops and resume preparation. The critique offered by the success of the IPS model to date is the focus on good matching, job development and actual job placement that is then supported, rather than job preparation that does not necessarily lead to work. While not everyone

Table 3 Study characteristics for cognitive behavioural therapy focused interventions in mild-moderate mental health populations

\begin{tabular}{|c|c|c|c|c|c|}
\hline Reference & Population & Intervention & Comparison & $\begin{array}{l}\text { Statistical power } \\
\text { of sample }\end{array}$ & Reported paid work outcomes \\
\hline $\begin{array}{l}\text { Kaldo et al, } \\
2017^{37}\end{array}$ & Depression & $\begin{array}{l}\text { Internet-based } \\
\text { cognitive } \\
\text { behavioural } \\
\text { therapy (ICBT) } \\
(n=38)\end{array}$ & $\begin{array}{l}\text { 1. Physical } \\
\text { exercise- } 60 \text { min, } 3 x \\
\text { per week }(n=40) \\
\text { 2. Treatment as } \\
\text { usual-standard care } \\
\text { for depression as } \\
\text { determined by general } \\
\text { practitioner }(n=40)\end{array}$ & $\begin{array}{l}\text { Sample size } \\
\text { calculation for main } \\
\text { study only (sample } \\
\text { size achieved). } \\
\text { Unemployed at } \\
\text { baseline subgroup } \\
\text { analysis small } \\
\text { sample }(n=118)\end{array}$ & $\begin{array}{l}\text { Employment status not significantly } \\
\text { different between ICBT group and } \\
\text { treatment as usual comparison } \\
\text { or between ICBT group and } \\
\text { physical exercise comparison at } \\
\text { 12-month follow-up in the subgroup } \\
\text { unemployed at baseline. }\end{array}$ \\
\hline $\begin{array}{l}\text { Himle et al, } \\
2014^{38}\end{array}$ & $\begin{array}{l}\text { Social } \\
\text { anxiety } \\
\text { disorder }\end{array}$ & $\begin{array}{l}\text { Work-related } \\
\text { cognitive- } \\
\text { behavioural } \\
\text { therapy }(n=29)\end{array}$ & $\begin{array}{l}\text { Usual care-this } \\
\text { normally included } \\
\text { career assessment, job } \\
\text { interview skills training } \\
\text { and job placement } \\
\text { assistance }(n=29)\end{array}$ & $\begin{array}{l}\text { Small sample } \\
\text { (pilot study). Not } \\
\text { powered to detect } \\
\text { differences. }\end{array}$ & $\begin{array}{l}\text { No significant difference between } \\
\text { groups in those who worked for pay } \\
\text { in } 12 \text { weeks prior to follow-up ( } 44 \\
\text { of the total } 58 \text { participants, specific } \\
\text { numbers by group not reported) } \\
\text { condition-related or the work hours of } \\
\text { working participants. }\end{array}$ \\
\hline
\end{tabular}


Table 4 Implementation context for cognitive behavioural therapy focused interventions

\begin{tabular}{|c|c|c|c|c|c|}
\hline Reference & $\begin{array}{l}\text { Long-term } \\
\text { condition }\end{array}$ & Country & $\begin{array}{l}\text { Community and } \\
\text { economic context }\end{array}$ & Intervention team & Key implementation information reported \\
\hline $\begin{array}{l}\text { Kaldo et al, } \\
2017^{37}\end{array}$ & Depression & Sweden & $\begin{array}{l}\text { Participants were } \\
\text { recruited from } \\
\text { primary care facilities } \\
\text { across six counties. } \\
\text { Intervention was } \\
\text { delivered on the } \\
\text { internet. People on } \\
\text { a 'disability pension' } \\
\text { were excluded. It } \\
\text { is unclear what this } \\
\text { means in a Swedish } \\
\text { context. }\end{array}$ & $\begin{array}{l}\text { Support provided for } \\
\text { participants using } \\
\text { the intervention by a } \\
\text { clinical psychologist } \\
\text { and a final-year } \\
\text { clinical psychology } \\
\text { student under } \\
\text { supervision. }\end{array}$ & $\begin{array}{l}\text { 'Before treatment, patients received a short phone } \\
\text { call from their therapists, who explained the treatment } \\
\text { process and helped with technical issues. They also filled } \\
\text { in several online questionnaires regarding depression, } \\
\text { worry, panic attacks, social anxiety, stress, insomnia, } \\
\text { pain and work-related problems.' There were 'three } \\
\text { introductory modules addressing problems related to } \\
\text { depressive symptoms, such as inactivity and avoidance } \\
\text { behaviours, the subsequent modules were tailored to } \\
\text { the patient's specific clinical profile, mainly based on } \\
\text { the areas mentioned above. In total, } 34 \text { modules were } \\
\text { available and } 30 \text { of these were used to individually tailor } \\
\text { the treatment.' 'four of the modules aimed at managing } \\
\text { problems related to work and sick leave: (one was } \\
\text { focused on) finding a new job, which participants without } \\
\text { employment could receive this module about the job } \\
\text { seeking process and homework assignments about } \\
\text { scheduling job seeking.' (p55) }\end{array}$ \\
\hline $\begin{array}{l}\text { Himle et al, } \\
2014^{38}\end{array}$ & $\begin{array}{l}\text { Social } \\
\text { anxiety } \\
\text { disorder } \\
\text { (SAD) }\end{array}$ & USA & $\begin{array}{l}\text { Delivered at } \\
\text { a vocational } \\
\text { rehabilitation centre } \\
\text { in Detroit. }\end{array}$ & $\begin{array}{l}\text { Delivered by } \\
\text { vocational services } \\
\text { professionals who } \\
\text { had been trained in } \\
\text { the use of cognitive } \\
\text { behavioural therapy } \\
\text { by specialists in CBT } \\
\text { for anxiety disorders } \\
\text { (30-50hours training } \\
\text { each plus weekly } \\
\text { supervision). }\end{array}$ & $\begin{array}{l}\text { 'Session } 1 \text { of WCBT (work-related cognitive behavioural } \\
\text { therapy) involves psychoeducation related to SAD and } \\
\text { its effect on employment. Session } 2 \text { primarily involves } \\
\text { instruction in the identification of automatic thoughts. } \\
\text { Session } 3 \text { involves further discussion about how SAD } \\
\text { relates to the world of work and instructs participants } \\
\text { in constructing rational responses to their automatic } \\
\text { thoughts. Sessions } 4-8 \text { include a psychoeducational } \\
\text { topic related to the world of work, in-session exposure } \\
\text { as well as cognitive restructuring, and homework } \\
\text { exercise planning'. (p172) }\end{array}$ \\
\hline
\end{tabular}

will require services of the intensity that IPS was designed for, these studies indicate that the principles themselves could be applied in a wider context. There is still considerable work to do to determine how IPS is best adapted for populations other than for people in specialist mental health and addiction services, and the extent to which IPS fidelity indicators need to be amended for less intensive contexts. Further studies will help address these issues. In addition, further large, well-conducted clinical trials are needed to strengthen the evidence on the effectiveness of vocational interventions for people living with mild to moderate mental health conditions, ideally with longer follow-up periods to track the sustainability of employment outcomes over time.

Table 5 Summary of study characteristics for other interventions in mild-moderate mental health populations

\begin{tabular}{|c|c|c|c|c|c|}
\hline Reference & Population & Intervention & Comparison & $\begin{array}{l}\text { Statistical power } \\
\text { of sample }\end{array}$ & Reported paid work outcomes \\
\hline $\begin{array}{l}\text { Audhoe } \\
2016^{45}\end{array}$ & $\begin{array}{l}\text { Netherlands People } \\
\text { identified to have } \\
\text { 'psychological } \\
\text { problems' who were } \\
\text { unemployed when } \\
\text { 'sick listed' or had } \\
\text { temporary contracts } \\
\text { that will expire. }\end{array}$ & $\begin{array}{l}\text { 'Brainwork' } \\
\text { intervention } \\
(n=164)\end{array}$ & $\begin{array}{l}\text { Usual care- } \\
\text { sickness } \\
\text { absence } \\
\text { counselling } \\
(n=156)\end{array}$ & $\begin{array}{l}\text { Considered } \\
\text { calculation. } \\
\text { Calculated } \\
\text { sample size } \\
\text { achieved. }\end{array}$ & $\begin{array}{l}\text { Duration of sick leave lower ( } 171 \text { days) in the } \\
\text { intervention group than in the usual care control } \\
\text { group ( } 185 \text { days) but difference not significant. Mean } \\
\text { hours in paid employment for those working during } \\
\text { the } 6 \text {-month follow-up period was significantly } \\
\text { greater in the control group than the intervention } \\
\text { group ( } 443 \text { hours vs } 257 \text { hours; } p=0.005 \text { ). }\end{array}$ \\
\hline $\begin{array}{l}\text { Drebing et al, } \\
2007^{40}\end{array}$ & $\begin{array}{l}\text { US Veterans with } \\
\text { dual diagnosis } \\
\text { (Mental health } \\
\text { diagnoses majority } \\
\text { moderate). }\end{array}$ & $\begin{array}{l}\text { Incentive-based } \\
\text { Contingency } \\
\text { Management } \\
\text { added to } \\
\text { vocational } \\
\text { rehabilitation } \\
(n=50)\end{array}$ & $\begin{array}{l}\text { Vocational } \\
\text { rehabilitation } \\
\text { only }(n=50)\end{array}$ & $\begin{array}{l}\text { Small sample } \\
\text { size. No } \\
\text { calculation } \\
\text { reported. }\end{array}$ & $\begin{array}{l}\text { Significantly more intervention group participants } \\
(50 \%) \text { competitively employed compared with } \\
\text { vocational rehabilitation only participants }(28 \%) \text { at } \\
9 \text {-month follow-up; } p<0.05 \text {. Tenure no significant } \\
\text { difference, but this analysis was limited by low } \\
\text { number in employment and short follow-up period. }\end{array}$ \\
\hline
\end{tabular}




\section{CONCLUSION}

There is very low quality evidence that IPS helps unemployed people living with mild to moderate mental health conditions gain competitive employment over an $8-24$ month period. There is currently insufficient evidence to draw conclusions regarding the effectiveness of other forms of vocational rehabilitation for people living with mild to moderate mental health conditions.

\section{Author affiliations}

${ }^{1}$ Centre for Person Centred Research, School of Clinical Sciences, AUT University, Auckland, New Zealand

${ }^{2}$ School of Health and Social Development, Deakin University, Burwood, Victoria, Australia

${ }^{3}$ Department of Social Work, Child Welfare and Social Policy, Oslo Metropolitan University, Oslo, Norway

${ }^{4}$ Department of Medicine, University of Otago, Wellington, New Zealand

Acknowledgements Thank you to the leads of the stakeholder reference groups who contributed to this work: Dr Helen Lockett, Sean Gray, Dr Matire Harwood, Neil Woodhams; and also to the contributors in the stakeholder reference group meetings.

Contributors JF had oversight of the review and was involved in protocol development, search, screening, risk of bias assessment, data extraction and synthesis and write up. DA was involved in protocol development, search, screening, risk of bias assessment, data extraction and synthesis. KR was involved in search, screening and risk of bias assessment. MK was involved in data extraction and synthesis. WL was involved in protocol development, data analysis, synthesis and write up. All authors approved the final manuscript for submission.

Funding This work was supported by New Zealand Ministry of Social Development and Health Research Council partnership grant number 18/804.

Competing interests None declared.

Patient consent for publication Not required.

Provenance and peer review Not commissioned; externally peer reviewed.

Data availability statement Data sharing not applicable as no data sets generated and/or analysed for this study.

Supplemental material This content has been supplied by the author(s). It has not been vetted by BMJ Publishing Group Limited (BMJ) and may not have been peer-reviewed. Any opinions or recommendations discussed are solely those of the author(s) and are not endorsed by BMJ. BMJ disclaims all liability and responsibility arising from any reliance placed on the content. Where the content includes any translated material, BMJ does not warrant the accuracy and reliability of the translations (including but not limited to local regulations, clinical guidelines, terminology, drug names and drug dosages), and is not responsible for any error and/or omissions arising from translation and adaptation or otherwise.

Open access This is an open access article distributed in accordance with the Creative Commons Attribution Non Commercial (CC BY-NC 4.0) license, which permits others to distribute, remix, adapt, build upon this work non-commercially, and license their derivative works on different terms, provided the original work is properly cited, appropriate credit is given, any changes made indicated, and the use is non-commercial. See: http://creativecommons.org/licenses/by-nc/4.0/.

\section{ORCID iDs}

Joanna K Fadyl http://orcid.org/0000-0001-7678-9122

William M M Levack http://orcid.org/0000-0001-6631-908X

\section{REFERENCES}

1 Fadyl JK, Payne D. Socially constructed 'value' and vocational experiences following neurological injury. Disabil Rehabil 2016;38:2165-77.

2 Harlan SL, Robert PM. The social construction of disability in organizations. Work Occup 1998;25:397-435.

3 Louvet E. Social judgment toward job applicants with disabilities: perception of personal qualities and competences. Rehabil Psychol 2007;52:297-303.
4 Pacheco G, Page D, Webber DJ. Mental and physical health: re-assessing the relationship with employment propensity. Work Employm Soc 2014;28:407-29.

5 Schur L, Kruse D, Blasi J, et al. Is disability disabling in all workplaces? workplace disparities and corporate culture. Ind Relat 2009;48:381-410.

6 Wehman PH, Revell WG, Kregel J, et al. Supported employment: an alternative model for vocational rehabilitation of persons with severe neurologic, psychiatric, or physical disability. Arch Phys Med Rehabil 1991;72:101-5.

7 Bond GR. Principles of the individual placement and support model: empirical support. Psychiatr Rehabil J 1998;22:11-23.

8 Becker DR, Swanson S, Bond GR, et al. Evidence-based supported employment fidelity review manual. Lebanon, $\mathrm{NH}$ : Dartmouth Psychiatric Research Center, 2008.

9 Bond GR, Becker DR, Drake RE, et al. A fidelity scale for the individual placement and support model of supported employment. Rehab Counsel Bulletin 1997;40:265-84

10 Bond GR, Peterson AE, Becker DR, et al. Validation of the revised individual placement and support fidelity scale (IPS-25). Psychiatr Serv 2012;63:758-63.

11 Bond GR, Drake RE, Pogue JA. Expanding individual placement and support to populations with conditions and disorders other than serious mental illness. Psychiatr Serv 2019;70:488-98.

12 Hellström L, Bech P, Hjorthøj C, et al. Effect on return to work or education of individual placement and support modified for people with mood and anxiety disorders: results of a randomised clinical trial. Occup Environ Med 2017;74:717-25.

13 Poremski D, Rabouin D, Latimer E. A randomised controlled trial of evidence based supported employment for people who have recently been homeless and have a mental illness. Adm Policy Ment Health 2017;44:217-24.

14 Bejerholm U, Larsson ME, Johanson S. Supported employment adapted for people with affective disorders-A randomized controlled trial. J Affect Disord 2017;207:212-20.

15 Carmona VR, Gómez-Benito J, Huedo-Medina TB, et al. Employment outcomes for people with schizophrenia spectrum disorder: a metaanalysis of randomized controlled trials. Int J Occup Med Environ Health 2017:30:345-66.

16 Chan JYC, Hirai HW, Tsoi KKF. Can computer-assisted cognitive remediation improve employment and productivity outcomes of patients with severe mental illness? A meta-analysis of prospective controlled trials. J Psychiatr Res 2015;68:293-300.

17 Crowther R, Marshall M, Bond G, et al. Vocational rehabilitation for people with severe mental illness. Cochrane Database Syst Rev 2001;2:CD003080.

18 Dewa CS, Loong D, Trojanowski L, et al. The effectiveness of augmented versus standard individual placement and support programs in terms of employment: a systematic literature review. $J$ Ment Health 2018;27:174-83.

19 Heffernan J, Pilkington P. Supported employment for persons with mental illness: systematic review of the effectiveness of individual placement and support in the UK. $J$ Ment Health 2011;20:368-80.

20 Kinoshita Y, Furukawa TA, Kinoshita K, et al. Supported employment for adults with severe mental illness. Cochrane Database System Rev 2013;75:CD008297.

21 Marshall T, Goldberg RW, Braude L, et al. Supported employment: assessing the evidence. Psychiatr Serv 2014;65:16-23.

22 Modini M, Tan L, Brinchmann B, et al. Supported employment for people with severe mental illness: systematic review and metaanalysis of the International evidence. Br J Psychiatry 2016;209:14-22.

23 Muñoz-Murillo A, Esteban E, Ávila CC, et al. Furthering the evidence of the effectiveness of employment strategies for people with mental disorders in Europe: a systematic review. Int $J$ Environ Res Public Health 2018;15

24 Suijkerbuijk YB, Schaafsma FG, van Mechelen JC, et al. Interventions for obtaining and maintaining employment in adults with severe mental illness, a network meta-analysis. Cochrane Database Syst Rev 2017;9:CD011867.

25 Shea BJ, Reeves BC, Wells G, et al. AMSTAR 2: a critical appraisal tool for systematic reviews that include randomised or non-randomised studies of healthcare interventions, or both. BMJ 2017;358:j4008.

26 Steel Z, Marnane C, Iranpour C, et al. The global prevalence of common mental disorders: a systematic review and meta-analysis 1980-2013. Int J Epidemiol 2014;43:476-93.

27 Reme SE, Grasdal AL, Løvvik C, et al. Work-focused cognitivebehavioural therapy and individual job support to increase work participation in common mental disorders: a randomised controlled multicentre trial. Occup Environ Med 2015;72:745-52. 
28 Knudsen AK, Harvey SB, Mykletun A, et al. Common mental disorders and long-term sickness absence in a general working population. The Hordaland health study. Acta Psychiatr Scand 2013;127:287-97.

29 Blank L, Peters J, Pickvance S, et al. A systematic review of the factors which predict return to work for people suffering episodes of poor mental health. J Occup Rehabil 2008;18:27-34.

30 Clegg S. Evidence-based practice in educational research: a critical realist critique of systematic review. Br J Sociol Educ 2005;26:415-28.

31 Pollock A, Campbell P, Struthers C, et al. Stakeholder involvement in systematic reviews: a protocol for a systematic review of methods, outcomes and effects. Res Involv Engagem 2017;3:9.

32 Higgins JPT, Thomas J, Chandler J, et al. Cochrane handbook for systematic reviews of interventions version 6.0 (updated July 2019): cochrane, 2019.

33 Reed K, Fadyl JK, Anstiss D. Protocol: effectiveness of interventions to support people with mild-moderate mental health conditions gain paid work - systematic review. Tuwhera Open Research, Auckland University of Technology, 2019. http://hdl.handle.net/10292/12897

34 International Labour Organisation. Resolution concerning statistics of the economically active population, employment, unemployment and underemployment, 1982.

35 Higgins JPT, Altman DG, Gøtzsche PC, et al. The Cochrane collaboration's tool for assessing risk of bias in randomised trials. BMJ 2011;343:d5928.

36 Schünemann H, Brożek J, Guyatt G. GRADE handbook for grading quality of evidence and strength of recommendations. The GRADE Working Group, 2013.

37 Kaldo V, Lundin A, Hallgren M, et al. Effects of Internet-based cognitive behavioural therapy and physical exercise on sick leave and employment in primary care patients with depression: two subgroup analyses. Occup Environ Med 2018;75:52-8.

38 Himle JA, Bybee D, Steinberger E, et al. Work-related CBT versus vocational services as usual for unemployed persons with social anxiety disorder: a randomized controlled pilot trial. Behav Res Ther 2014;63:169-76 https://dx.doi.org/
39 Reme SE, Monstad K, Fyhn T, et al. A randomized controlled multicenter trial of individual placement and support for patients with moderate-to-severe mental illness. Scand J Work Environ Health 2019;45:33-41.

40 Drebing CE, Van Ormer EA, Mueller L, et al. Adding contingency management intervention to vocational rehabilitation: outcomes for dually diagnosed veterans. J Rehabil Res Dev 2007;44:851-65.

41 Audhoe SS, Nieuwenhuijsen K, Hoving JL, et al. The effectiveness of the 'brainwork intervention' in reducing sick leave for unemployed workers with psychological problems: design of a controlled clinical trial. BMC Public Health 2015;15:377.

42 Davis LL, Kyriakides TC, Suris AM, et al. Effect of evidence-based supported employment vs transitional work on achieving steady work among veterans with posttraumatic stress disorder: a randomized clinical trial. JAMA Psychiatry 2018;75:316-24.

43 Davis LL, Leon AC, Toscano R, et al. A randomized controlled trial of supported employment among veterans with posttraumatic stress disorder. Psychiatr Serv 2012;63:464-70.

44 Poremski D, Whitley R, Latimer E. Building trust with people receiving supported employment and housing first services. Psychiatr Rehabil J 2016;39:20-6.

45 Audhoe SS. Promoting work participation of non-permanent workers with psychological problems: an evidence-based approach to occupational health care. Universiteit van Amsterdam, 2016.

46 Priest $\mathrm{B}$, Lockett $\mathrm{H}$. Working at the interface between science and culture: the enablers and barriers to individual placement and support implementation in Aotearoa/New Zealand. Psychiatr Rehabil $J$ 2020;43:40-52.

47 Pelizza L, Ficarelli ML, Vignali E, et al. Implementation of individual placement and support in Italy: the Reggio Emilia experience. Community Ment Health J 2020;56:1128-38.

48 Hellström L, Bech P, Nordentoft M, et al. The effect of IPS-modified, an early intervention for people with mood and anxiety disorders: study protocol for a randomised clinical superiority trial. Trials 2013;14:442. 